\title{
Mauritinus seferi Bondar, 1960: bionomy, description of immature stages and redescription of adult (Coleoptera, Curculionidae)
}

\author{
Márcio Luís Leitão Barbosa ${ }^{1}$ \\ Roberta de Melo Valente ${ }^{2}$
}

\begin{abstract}
Mature larvae of Mauritinus seferi Bondar, 1960 were collected in the mesocarp of murity palm (Mauritia flexuosa Linnaeus), in the State of Pará, Brazil. Larvae were reared to pupa and adults in the laboratory. Mature larva and pupa are described and adult redescribed. Adult and immature are illustrated for the first time. Observations about bionomy are included and discussed.
\end{abstract}

Keywords. Baridinae; bionomy; Mauritia flexuosa; Mauritinus seferi; weevil.

\section{INTRODUCTION}

The genus Mauritinus and its only species, $M$. seferi, were described by BONDAR (1960), based on 4 larvae reared from fruits of murity palm (Mauritia flexuosa L.), collected in Cametá, Pará State, Brazil. After BondAR's work no other information about this weevil has been published.

Mature larvae of Mauritinus seferi were collected and reared in the laboratory to observe the biological cycle and the damage caused by its larvae to fruits of murity palm. Mature larvae and pupae are described and adults are redescribed.

\section{MATERIALAND METHODS}

Collections were carried out in two localities in Pará State, Brazil: São João de Pirabas (Pedrinhas), in August 1995; and Estação Científica Ferreira Penna (ECFPn), Melgaço (Caxiuanã), in May and August 1998, and January, 1999.

The fruits (green, ripe and senescent) collected on the ground were stored in plastic bags, labeled and brought to the laboratory in a Styrofoam box with hipergel to maintain the temperature at an appropriate level. In the laboratory, some of the Curculionidae larvae were killed in boiling water and fixed in $70 \%$ alcohol. Other larvae were reared in a glass bottle with a ripe fruit and sterile sand, necessary for pupation. Pupae obtained were transferred to individual glass bottles with sterile sand. Some of the pupae were killed and fixed as described for the larvae. Adults obtained were fed with water and sugar, and after the teneral stage, killed with ethyl acetate, pinned and labeled. Larvae, pupae and adults are deposited in the entomological collection of the Museu Paraense Emílio Goeldi (MPEG).

To observe if adults of $M$. seferi visit inflorescences, 16 species of palms were sampled in Caxiuanã: Mauritia flexuosa L. [murity palm], Euterpe oleracea Mart. [açaizeiro], Oenocarpus distichus Mart. [bacabeira], Mauritiella armata (Mart.) Burret [caranã], Attalea spectabilis Mart. [curuá], Attalea maripa (Aubl.) Mart. [inajá], Bactris brongniartii Mart. [marajá], Bactris campestris Poepp. ex Mart. [marajá do igapó], Bactris acanthocarpa Mart. [marajá da terra], Bactris elegans Barb. Rodr. [marajazinho], Acrocomia aculeata (Jacq.) Lodd. ex Mart. [mucajá], Astrocaryum gynacanthum Mart. [mumbaca], Astrocaryum paramaca Mart. [palha preta], Syagrus inajai (Spruce) Becc. [paxiubinha], Astrocaryum vulgare Mart. [tucumã], Geonoma maxima (Poit.) Kunth [ubinrana]. The inflorescences were placed in plastic bags and cut from the palm. The specimens were killed with ethyl acetate. In laboratory, weevils were sorted, pinned, labeled and identified.

The following procedures were used to measure weevils studied: Larva- length of head capsule, from fronto-clipeal suture

1. Coordenação de Pesquisas em Entomologia, Instituto Nacional de Pesquisas da Amazônia. Av. André Araújo, 2936, Cx. Postal 478, 69011-970 Manaus-AM, Brazil. E-mail: marciolb@inpa.gov.br

2. Departamento de Biologia, Centro de Ciências Biológicas, Universidade Federal do Pará. Rua Augusto Corrêa, 1, 66075-110 Belém-PA, Brazil. E-mail: rvalent@nautilus.com.br 
to posterior margin of head, in dorsal view. Pupa- length of body, from the apex of prothorax to apex of abdomen, without adding the setiferous tubercles of segment IX, in dorsal view; length of prothorax, from the apex to base without the basal lobe, along the median line, in dorsal view. Adult- length of rostrum, two measurements, the first, from the apex to antennal insertion and, the second, from this point to base, without adding the mouth parts, in lateral view; length of pronotum, from the apex to base, along the median line, without the basal lobe; length of elytra, along the interval III; length of ventrite I, was measured on line traced a little after the cavity of the posterior coxae; length of ventrites II-V, along the median line. Most of measurements were transformed to proportions and presented in the descriptions.

\section{RESULTSANDDISCUSSION}

\section{Bionomy}

Green (miscarried), ripe and senescent (rotten) fruits of the murity palm were collected. On examination of the collected fruits, we did not observe scars or marks that indicate infestation by immature stages of $M$. seferi or by other insects, except for senescent fruits that were totally infested by larvae of Nitidulidae (Coleoptera) and larvae of Diptera. The larvae of Nitidulidae and Diptera feed on the mesocarp (the edible, thickened orange part of the fruits), making the scales that cover the epicarp easily detachable.

In the green and ripe fruits, the scales that cover the epicarp are very resistant and stuck to the mesocarp. In this case, the observation of the mesocarp, to search for immature stages of $M$. seferi, was made with the aid of small knives or tweezers. Immatures of $M$. seferi were not found in the green fruits, while in the ripe fruits only larvae of last instars were found; larvae of other instars or pupae were not found.

The larvae of $M$. seferi build galleries and feed on the mesocarp, making them unfit for human consumption (manufacture of juices and sweets). In the infested fruits, we always found two larvae of $M$. seferi per fruit, and these fruits were never infested with other species of insects (immatures or adults). These observations do not seem to us to be the result of chance, but indicate that females lay two eggs systematically in each fruit and should leave some type of chemical sign to prevent other females of $M$. seferi and other species of insects from laying eggs on the same fruits. This same kind of behavior has already been observed in others species of Curculionidae, and it seems to be very important to avoid competition for space, food and to prevent the complete destruction or rottenness of the fruits before the pupation of larvae (ANDERSON 1993).

The percentages of fruits infested by larvae of $M$. seferi were quite different among the studied localities. In Pedrinhas, infestation was found in about $90 \%$ of the fruits collected, while in Caxiuanã the infestation was about $10 \%$. At the moment, we still do not have an explanation of why such a difference exists in the percentage of fruit infestation.

Since we did not find larvae of other stages, it is probable that females of $M$. seferi lay their eggs on the fruits that are just beginning to maturate, because these fruits already display a developed mesocarp and are ready to serve as food for larvae. We think that the growth of larval instars follows ripening of fruits, so that when a fruit fall on the ground, the larvae would be in the last development stage and would be ready to begin the pupation process in the soil. We considered that the following evidence indicates synchronization between the development of the immature stages of $M$. seferi and the ripening of the fruits: 1. We did not find larvae in green or senescent fruits because they did not display developed or available mesocarp as food for the weevil larvae; 2 . The initial stages of development feed on mesocarp, but without causing complete destruction or rottenness of the fruit. This avoids deterioration of the ripening fruits that could threaten the development of other stages; and 3. The larvae of the last stage feed on mesocarp, but without damaging the scales that cover the fruit and protect the larvae against the invasion by natural enemies through the entrance galleries. Other authors (BONDAR 1941, 1943; Valente \& Gorayeb 1994) also reported the synchronization between the immature stages of Curculionidae and the development of fruits.

Larvae reared in the laboratory changed to pupae in sterilized sand, with the exception of two larvae that changed to pupae in the mesocarp. Pupation in the fruit probable happened due to adverse conditions in the laboratory, because pupae were not observed in the fruits under natural conditions in the field.

The larvae of $M$. seferi are monophagous, as far as known.

It is interesting that adults of $M$. seferi were not found in the flowers of the 16 species of palm trees collected in Caxiuanã. Therefore, the host plant of adults is still unknown.

The geographical distribution of $M$. seferi, which was restricted to the type locality, is now enlarged to include Melgaço (Caxiuanã) and São João de Pirabas (Pedrinhas) (Pará, Brazil). It probable that M. seferi show a wider geographical distribution, coincident with that of M. flexuosa.

\section{Mauritinus seferi Bondar, 1960}

\section{Mature larva (Figs. 1-13)}

Length 5.2-11.3 mm, yellowish white, curved dorsoventrally (Fig. 1), body covered with fine brown setae.

Head capsule (Fig. 4) dark-brown, 1.1-1.2 times wider than long, broadest in the middle, rounded posteriorly, hipognathus and sclerotized. Coronal suture more than one-half as long as head. Frontal suture complete, U-shaped, sinuous at base and slightly angulate before the apex. Paraepicranial sutures elongate beyond frontal suture. Endocarina more than onehalf as long as frons. Antennae (Fig. 6) 1-segmented; membranous article with a conical accessory sensory appendage and 6 minute conic sensillae. Epistome strongly sclerotized. Frontoclypeal suture shallow. Stemmata absent. Frons subtriangular-shaped; with 5 pairs of frontal epicranial setae (fes): fes 1 and fes 2 minute, fes 3 very short, fes 4 and fes 5 longer and subequal in length; and 2 pairs of sensillae, one pair 

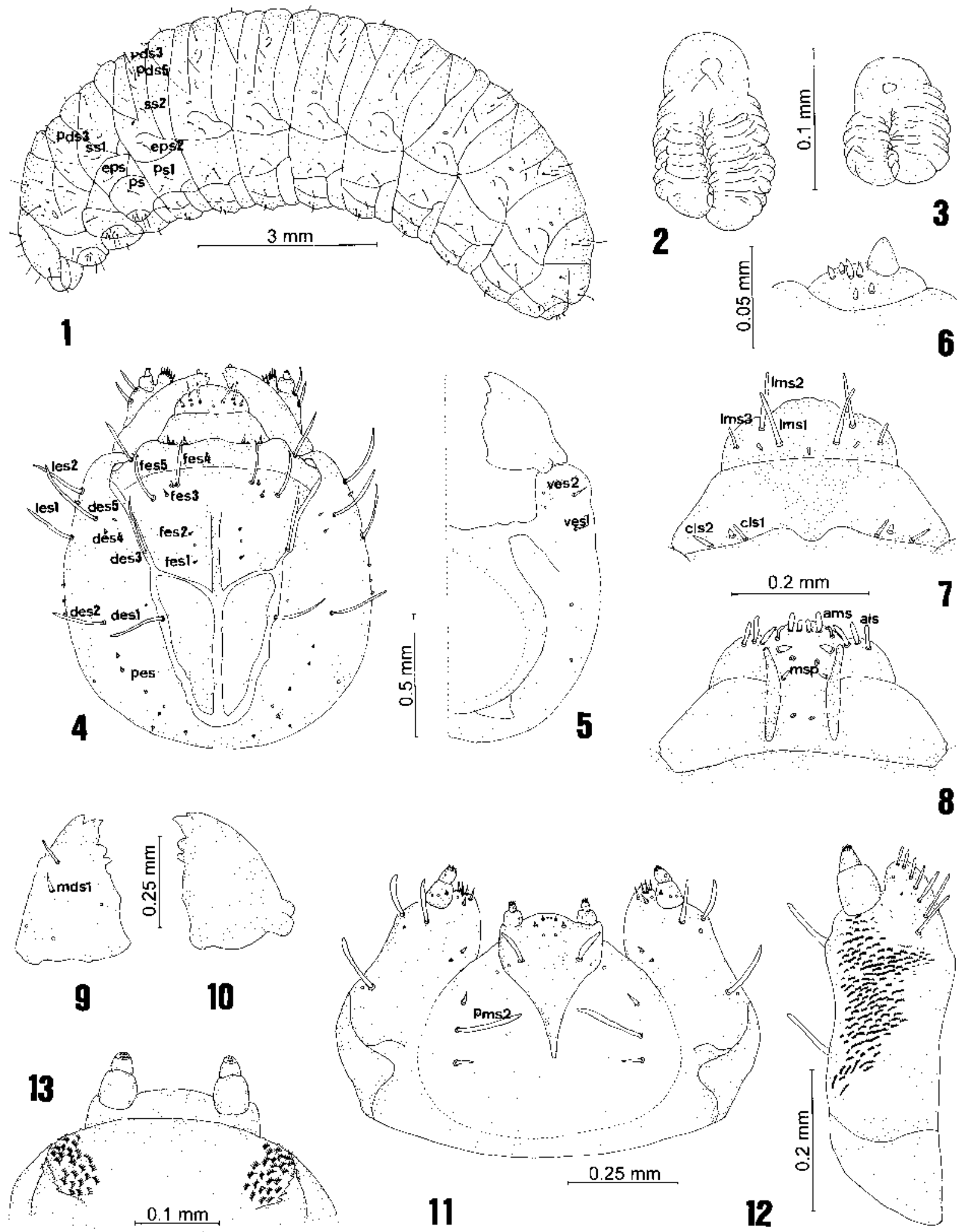

Figs. 1-13. Mauritinus seferi, mature larva: 1, lateral view; $\mathbf{2}$, prothoracic spiracle; $\mathbf{3}$, abdominal spiracle; $\mathbf{4}$, head capsule (dorsal view); $\mathbf{5}$, head capsule (ventral view); 6, antenna. 7, clypeus and labrum; 8, epipharynx; 9. left mandible (dorsal view); 10, left mandible (ventral view); 11, maxilla and labium; 12, maxilla (dorsal view); 13, hipopharynx. des= dorsal epicranial setae; eps = epipleural setae; fes = frontal epicranial setae; les = lateral epicranial setae; $\mathrm{pds}=$ postdorsal setae; pes = posterior epicranial setae; $\mathrm{ps}=$ pleural setae; $\mathrm{ss}=$ spiracular setae; ves $=$ ventral epicranial setae. als $=$ anterolateral setae; ams = anteriomedian setae; cls = clypeal setae; lms = labral setae; $\mathrm{mds}=$ mandibular setae; $\mathrm{msp}=$ median spines; $\mathrm{pms}=$ posmental setae. 
between fes 1 and fes 2 and other lateral to fes4. Dorsal epicranium with 5 pairs of dorsal epicranial setae (des): des1, des 2 , des 3 and des 5 long (des 1 and des 3 placed within paraepicranial and frontal sutures, respectively), des 4 minute; and 2 pairs of sensillae, one pair close to des 1 and other forming a triangle with des 4 and des5. Lateral epicranium with 2 pairs of long lateral epicranial setae (les); and 4 pairs of sensillae, 3 pairs median and 1 between les 1 and les2. Posterior epicranium with 6 pairs of minute posterior epicranial setae (pes); and 2 pairs of sensillae. Ventral epicranium (Fig. 5) with 2 pairs of short ventral epicranial setae (ves); and 4 pairs of sensillae, 2 pairs median and 2 pairs close to ves2. Clypeus (Fig. 7) transversal, about 4.0 times wider than long; almost totally sclerotized; with 2 pairs of very short spatuliform clypeal setae (cls); and 1 pair of sensillum, each one placed between cls 1 and cls2.

Mouth parts retracted. Labrum (Fig. 7) transversal, about 3.0 times wider than long; anterior margin trilobed and with a slight median protuberance; base sclerotized; apex membranous; with 3 spatuliform labral setae (lms) forming a triangle: $1 \mathrm{~ms} 1$ and $\operatorname{lms} 2$ long ( $\operatorname{lms} 1$ discal), $\operatorname{lms} 3$ short; and a basal row of 3 sensillae, a median and another between $1 \mathrm{~ms} 1$ and lms3. Epipharynx (Fig. 8) most sclerotized; with 3 larger anterolateral setae (als) on each side; 6 anteromedian setae (ams); 2 pairs of median spines (msp); 2 pairs of sensorial spots, one posterior and another between median spines; epipharyngeal bracon large, about 0.7 times as long as epipharynx, broadest in the middle, subparallel and separated at base. Gula and subgula suture absent. Occipital foramen large. Postoccipital condyles large, obtuse, angulate and pigmented. Hypostomal rods absent. Mandibles (Figs. 9-10) dark-brown, concave and subtriangular-shaped, strongly sclerotized, symmetrical; with 2 sharp-pointed apical teeth and 2 obtuse mesal teeth; dorsal region bearing 2 long mandibular setae (mds) aligned longitudinally and 3 sensillae situated below mds1. Maxillae (Fig. 11) with rounded mala; ventral region of mala with 5 distal spatuliform setae and 1 basal sensillum; dorsal region of maxila (Fig. 12) covered with microtrichia and with a marginal row of 7 spatuliform setae, becoming longer from apex to base. Maxillary palpi 2-segmented; longer than mala; segment I transversal, with 1 minute seta and 2 sensillae; segment II shorter, conic, with 1 basal sensillum and 1 apical cluster of microsensillae. Palpifer membranous. Stipes: ventral region (Fig. 11) with 4 setae: 1 longer sub-basal seta, 2 long distal setae and 1 minute median seta; and 3 sensillae: a close to sub-basal setae, a forming a triangle with distal setae and another close to median setae. Cardo not divided, transversal, glabrous. Labial palpi 2-segmented; segment I transversal and with 1 basal sensillum; segment II shorter, conic, with 1 basal sensillum and 1 apical cluster of microsensillae. Palpiger membranous. Premental sclerite (Fig. 11) sclerotized, elongate, strongly narrowing posteriorly; with 2 setae: very short anterior seta and long posterior seta; 2 sensillae, one close to anterior seta and other close to posterior seta; membranous ligula, with 1 short seta and 1 sensillum. Posmentum membranous; with 3 posmental setae (pms): pms1 and pms 3 short and pms 2 long; and 1 sensillum close to premental sclerite. Hipopharynx (Fig. 13) small, sclerotized; hypopharyngeal scleroma absent; lateral edges with stripes of microtrichiae, which are curved down to the anterior and median region.

Thorax (Fig. 1). Prothorax transversal, about 1.2 times longer than mesothorax, not divided in dorsal view; with one pair of sclerotized anular-biforous spiracles (Fig. 2) presenting air tubes about 2.2 times as long as peritreme and curved dorsally; pronotum slightly sclerotized; with 11 setae each one side being, 3 short anterior (sometimes deciduous), 1 long median (sometimes deciduous), 1 short postero-median, and 6 lateral being, 2 long and 4 short and sometimes deciduous; spiracular and epipleural areas glabrous; pleural area slightly sclerotized and with 2 setae, anterior seta longer; pedal area with 6 setae being, 4 short and 2 long; eusternum slightly sclerotized and with 1 short seta; sternellum glabrous. Mesothorax and metathorax subequal in length; each one with 2 transversal dorsal folds; setation of meso- and metathorax similar (setae described on side of body only): prodorsum with 1 short seta; postdorsum with 4 postdorsal setae (pds), pds3 longer; alar area with 1 short seta; spiracular area with 2 spiracular setae (ss), ss 1 shorter and sometimes deciduous; epipleural and pleural areas each one with 1 long seta; pedal area with 6 setae being, 2 long and 4 short; eusternum with 1 short seta; sternellum glabrous.

Abdomen with segments I-IX visible dorsally. Segments IVIII with one pair of anular-biforous spiracles (Fig. 3), smaller than prothoracic spiracles and presenting air tubes about 3.5 times as long as peritreme, curved dorso-posteriorly on segment I and curved posteriorly on segments II-VIII. Segments IVII with 3 dorsal folds; folds not evident on segments VIII-IX; setation on abdominal segments I-VII similar (setae described on one side of body only): prodorsum with 1 short seta; median fold glabrous; postdorsum with 5 setae, pds 3 and pds 5 longer; spiracular area with 2 setae, ss 2 a little longer; epipleural area with 2 epipleural setae (eps), eps2 longer; pleural area with 2 pleural setae (ps), ps1 longer; pedal area with 1 short seta; eusternum with 2 short setae; sternellum glabrous. Segment VIII with 2 dorsal folds separated by slight groove; prodorsum glabrous; spiracular area with 1 very short seta; postdorsum, epipleural, pleural, pedal areas and the eusternum as segments I-VII; sternellum absent. Segment IX about 0.4 times as long as segment VIII; without evident dorsal folds; with 4 setae, 2 of which longer; eusternum with 2 short setae. Segment X reduced. Anus terminal, 4-lobed, lateral lobes with 3 minute setae.

Material examined: BRAZIL. Pará: São João de Pirabas, Pedrinhas, 4 specimens (1 dissected), 05.VIII.1995, R. M. Valente col. (em frutos de Mauritia flexuosa); Melgaço, Caxiuanã, ECFPn, 2 specimens (1 dissected), 25.V.1998, R. M. Valente col. (em frutos de Mauritia flexuosa) (MPEG).

\section{Pupa(Figs. 14-15)}

Length 6.0-7.6 mm, yellowish white, adecticous, exarate, covered by brown setiferous tubercles.

Head rounded, concealed by the prothorax; with 2 pairs of 

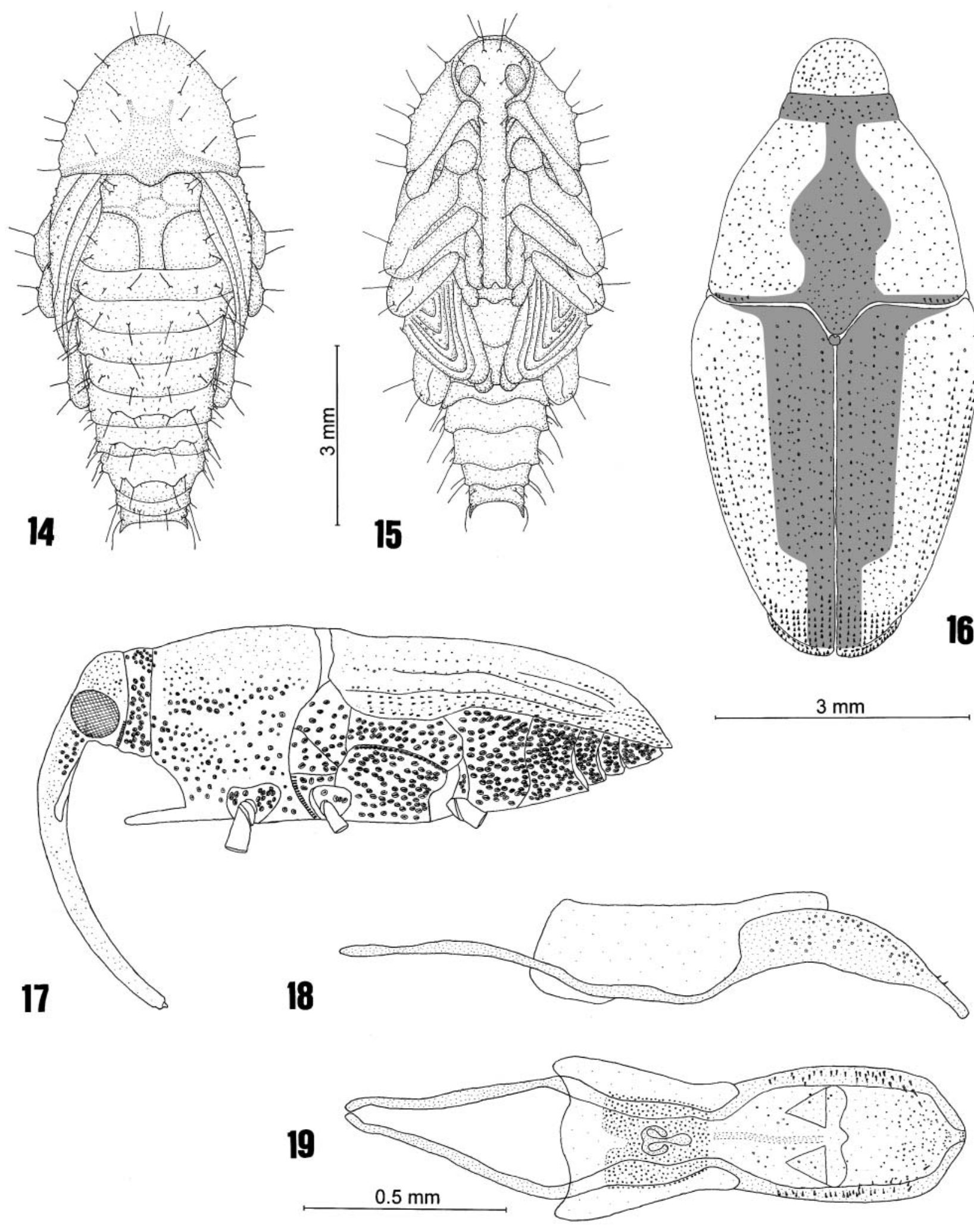

Figs. 14-19. Mauritinus seferi, pupa: 14, dorsal view; 15, ventral view. Adult (male): 16, dorsal view; 17, lateral view; 18, median lobe (lateral view); 19, median lobe (dorsal view). 
setiferous tubercles: one longer and situated above the eyes and the other close to the external edge of the eyes. Rostrum long, reaching the last tarsal segment of anterior legs; with 4 pairs of dorsal setiferous tubercles: the first to boundary of head, the second at base of antennae, the third at median region and the fourth at distal region.

Thorax. Prothorax subtriangular-shaped, rounded anteriorly; 1.4-1.5 times wider than long; basal region with 1 pair of lateral spiracles; with 10 pairs of setiferous tubercles: 2 antero-dorsal, 2 discal, 1 postero-dorsal and 5 lateral, one of which distinctly shorter than others. Mesothorax 2.7-3.0 times wider than long; with 2 pairs of dorsal setiferous tubercles. Metathorax 2.1-2.4 times wider than long; with 2 pairs of dorsal setiferous tubercles. Pterotheca with 28 to 43 setiferous tubercles: 13 to 21 forming a row on interval III; 5 to 8 at basal two-thirds of interval V; 2 to 4 at basal one-third of interval VII; 8 to 10 on interval IX being, 5 to 7 at basal one-third and 3 at distal onethird. Femora with 2 dorso-lateral setiferous tubercles.

Abdomen with 9 segments; 1 pair of lateral spiracles on segments I-VIII. Each very short setifero tubercle of segments I-II and VII-VIII is situated at base of long setifero tubercle. Segment I-VI subequal in length. Segment I with 4 pairs of setiferous tubercles: 1 long dorso-central; 1 short dorso-lateral; and 2 lateral, 1 of which very short and sometimes deciduous. Segment II with 5 pairs of setiferous tubercles: 1 long dorsocentral; 2 dorso-lateral, 1 of which very short and sometimes deciduous; and 2 lateral, 1 of which very short and sometimes deciduous. Segments III-VI with 10 pairs of setiferous tubercles: 4 dorso-central, 3 of which very short, generally deciduous being, a situated on base of the long pair; 2 dorso-lateral, 1 of which very short and sometimes deciduous; and 4 lateral, 2 of which very short. Segment VII about 1.8 times as long as segment VI; with 8 pairs of setiferous tubercles: 4 dorso-central, 2 of which very short and sometimes deciduous; and 4 lateral, 2 of which very short. Segment VIII about 0.5 times as long as segment VII; with 4 pairs of setiferous tubercles: 2 dorso-central, 1 of which very short; and 2 lateral, 1 of which very short. Segment IX about 0.5 times as long as segment VIII; with 4 pairs of setiferous tubercles: 1 short lateral, 1 long ventral and 2 dorso-lateral being, one pair distinctly wider and the other slender, longer and attached at base of the wider pair.

Variation. One specimen from Caxiuanã has head bearing 1 short setifero tubercle close to the pair situated above the eyes. Another specimen from Caxiuanã, has rostrum bearing 2 short setiferous tubercles close to the pair situated at base of antennae. One specimen from Pedrinhas has abdominal segment VIII bearing 1 long setifero tubercle close to pairs dorso-central.

Material examined: BRAZIL. Pará: São João de Pirabas, Pedrinhas, 2 specimens, 21.VIII.1995, R. M. Valente col. (criados em frutos de Mauritia flexuosa); Melgaço, Caxiuanã, ECFPn, 2 specimens, 02.VIII.1998, R. M. Valente col. (criados em frutos de Mauritia flexuosa); ditto, 1 specimen, 04.I.1999; ditto, 1 specimen, 06.I.1999 (MPEG).

\section{Adult (Figs. 16-25)}

Length (prothorax and elytron) male 5.1-6.2 mm; female 5.4-
$6.2 \mathrm{~mm}$ (Figs. 16-17). General coloration reddish brown to black; pronotum with a black spot along the middle (sometimes absent). Elytra with a black stripe from sutural interval to basal $3 / 4$ of interval IV or III. Integument covered with small scattered punctures, each with a whitish scale (sometimes deciduous) completely inserted into the puncture, being yellowish-white in the elytra and sides regions of abdomen.

Head (Fig. 17) black; rounded; with a dorso-median groove, deep or shallow. Eyes black, ovate, depressed, separated by distance smaller than rostrum base (male 0.7-0.8; female 0.81.0). Rostrum reddish brown to black, becoming lighter at the apex; smooth, shiny; punctures glabrous, becoming larger at basal region, which each puncture bearing a microscale; longer than prothorax (male 1.5; female 1.4-1.5); curved at base and in the antennal insertion area; basal $1 / 3$ cylindrical, distinctly wider and with a strong constriction at the end; distal $2 / 3$ flattened dorso-ventrally, broadest at the apex; with a median groove in the ventral region; antennal insertion pre-median (male; female $0.2-0.3$ ). Scrobe oblique, deep and wider at base. Antennae (Fig. 23) reddish brown to black; segment I (scape) clavate, shorter than rostrum (male; female 0.2), almost reaching the eyes when in repose in the scrobe; funicle (segments II-VIII) longer than scape (male 2.0; female 1.6) and with rows of long setae; segment II longer than III (male 1,2; female 1,3); segments $\mathrm{IV}+\mathrm{V}$ subequal in length to segment III; segments VI-VIII combined longer than segments IV+V (male; female 1.6); club longer than wide (male 1.7; female 1.8), subequal in length to segments VII+VIII; segments $\mathrm{X}+\mathrm{XI}$ subegual in length to segment IX.

Mouth parts (male; female). Mandibles (Fig. 20) dark-brown, strongly sclerotized, concave and subtriangular-shaped, symmetrical, movement in horizontal plane; with 2 falciform apical teeth and 1 mesal subquadrate tooth; dorsal face of each mandible with 2 sub-parallel rows of 3 setae and 3 sensillae, 1 close to acetabule and 2 close to mesal teeth. Maxilae (Fig. 21) with rounded mala, reaching the apex of segment I of palpus; lateral region with a row of 9 spatuliform setae, becoming larger from apex to base; ventral region with 3 short median setae; dorsal region with numerous long setae, becoming larger from apex to base. Palpifer membranous; with a row of 9 dorsal spatuliform setae. Cardo sclerotized, transversal; with 1 long latero-basal seta. Stipe elongate; with 3 setae: 2 antero-dorsal, 1 of which about 2 times longer, and 1 short postero-ventral; and with 2 latero-ventral sensillae, situated close to the setae. Maxilary palpi 3-segmented; segment I transversal, with 2 long latero-dorsal setae and 2 latero-ventral sensillae; segment II transversal, with 2 short setae: one dorsal and another laterodorsal, and 1 latero-ventral sensillum; segment III slightly elongate, with 2 latero-ventral sensillae and 1 apical cluster of microsensillae. Labium (Fig. 22) more sclerotized laterally. Prementum rounded; with 4 longs setae being, 3 lateral and 1 discal, distinctly smaller; and 2 dorso-basal sensillae. Labial palpi 3-segmented; segment I transversal, with 2 lateral setae, 1 of which about 2 times longer, and 1 dorso-basal sensillum; segment II transversal, with 1 minute latero-distal seta and 1 dorso-median sensillum; segment III elongate, with 2 dorso- 

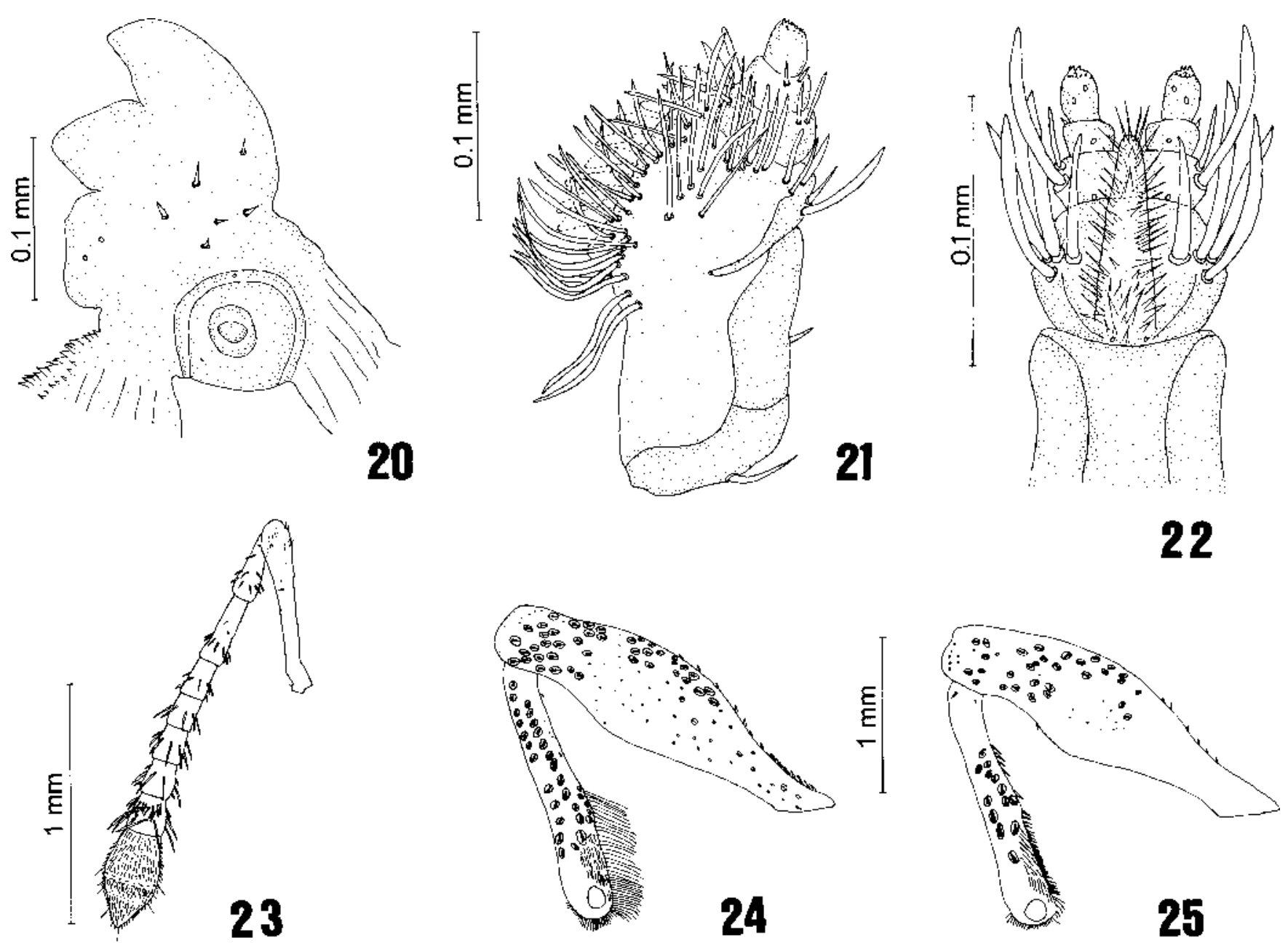

Figs. 20-25. Mauritinus seferi: 20, right mandible (dorsal view, male); 21, maxilla (dorsal view, male); 22, labium (dorsal view, male); 23, antenna (outer face, male); 24, anterior leg (male); 25, anterior leg (female). Figs. 20-22; 23-25, respectively to the same scale.

median sensillae and 1 apical cluster of microsensillae. Ligula developed and setose. Posmentum elongate.

Thorax (Figs. 16-17). Pronotum wider than long (male 1.4; female 1.3-1.4); reddish brown, black at apical constriction and posterior margin, and a black dorsomedian vittae (sometimes absent); punctures and scales larger at apical constriction and forming a row of scales in the posterior margin; broadest at posterior region; basal lobe evident and large; sinuous and carinate at base; sides subparallel at basal $2 / 3$ and convergent to distal $1 / 3$. Lateral region of prothorax reddish brown in the upper middle and from reddish brown to black in the lower middle. Prosternum reddish brown to black. Basisternum with an anterior row of silvered scales; males with 2 horn-like protuberances, variable in length, straight or curved down, joined by flattened trapezoid protuberance at base; females without horn-like protuberance or only with 2 very small protuberances. Sternellum trapezoid. Scutellum black, minute, grooved, subtrapezoid, finely punctate. Elytra a little wider than prothorax at base (male 1.1-1.3; female 1.1), longer than wide (male 1.2; female 1.2-1.3); reddish brown, black at sides and with a black strip from sutural interval to basal $3 / 4$ of interval IV or III; base sinuous and carinate; each elytron rounded at apex; 10 striae with shallow grooves, with deep evidently separated punctures, subequal in diameter, sparse, each one with a yellowish white scale; intervals with rows of punctures, subequal in diameter, irregularly placed, becoming larger towards apex and sides of elytra; intervals VII-VIII convex at base, intervals VIII-XI carinate at distal one-third, interval IX carinate to distal middle and interval $\mathrm{X}$ carinate in almost all length. Metasternum (male) depressed, (female) plane at central region.

Abdomen reddish brown to black; ventrites I+II longer than ventrites III-V combined (male 1.4; female 1.3-1.4); ventrite V subequal in length to ventrites III+IV (male 0.9-1.3; female 0.91.2). Pygidium not visible dorsally. Legs reddish brown to black. Anterior legs (Figs. 24-25) longer and more robust. Anterior coxae separated by 1.4-1.7 times its own diameter; external face with reddish brown inconspicuous striolae. All femora clavate, curved; inner face with a shallow groove to fit tibiae. Protibiae 
clavate, mucronate; inner face with a distal groove to receive the tarsomeres; corbel open; with a fringe of long yellowish brown setae on distal middle of inner face in the males. Mesoe metatibiae similar to protibiae, without fringe of yellowish brown setae. Tarsomeres I-IV pubescent in the ventral face; tarsomeres I-II triangular-shaped, subequal in length; tarsomere III strongly bilobed; tarsomere IV minute; tarsomere V curved and shorter than tarsomere I-II combined. Tarsal claws free, divergent at base, falciform and simple.

Aedeagus. Median lobe (Figs. 18-19) about 1.7 times longer than wide; sinuous anterior edge; inner sac large, densely covered with sensillae and presenting a sclerite with a bifid posterior projection and an anterior stem; operculate plates less sclerotized; apodemes about 1.8 times longer than median lobe.

Secondary sexual dimorphism. In males, the anterior region of prosternum has a pair of horn-like protuberances, variable in length. In females, the prosternum is plane or has only a pair of minute protuberances. Central region of mestasternum is depressed in males and plane in females. In males, the distal middle of inner face of protibiae presents a fringe of long yellowish brown setae, which is absent in females.

Variation. The specimens from Caxiuanã present a dark median spot in the prothorax, which is absent in the specimens from Pedrinhas. The specimens from Caxiuanã are, in average, larger than the specimen from Pedrinhas. According to BONDAR (1960), the integument is completely black, the scape reaches the eyes and the males are larger than females. However, the specimens studied are never completely black, except when fixed in alcohol; the scape does not reach the eyes and males (5.1-6.2 $\mathrm{mm}$ ) are similar in length to females (5.4-6.2 $\mathrm{mm})$.

Material examined: BRAZIL. Pará: São João de Pirabas, Pedrinhas,
3 males (1 dissected) and 1 female (only dissected mouth parts), 29.VIII.1995, R.M. Valente col. (criados em frutos de Mauritia flexuosa); Melgaço, Caxiuanã, ECFPn, 1 male and 2 females, 20.IX.1995, R.M. Valente col. (criados em frutos de Mauritia flexuosa); ditto, 2 males (2 dissected) and 2 females, 17.VII.1998; ditto, 1 female (only dissected mouth parts), 20.VIII.1998 (MPEG).

Acknowledgments. This work was supported by Fundo Estadual de Ciência e Tecnologia, Governo do Estado do Pará and Museu Paraense Emílio Goeldi. We are grateful to Universidade Federal do Pará for granting a research fellowship to MLLB. We would like to express our appreciation to: Dr. Sergio Antonio Vanin (Instituto de Biociências, Universidade de São Paulo) for his critical reading of the manuscript and suggestions; Dr Phillip Fearnside and Dr. Camilo Hurtado Guerrero (Instituto Nacional de Pesquisas da Amazônia), which corrected and improved the english version of this paper; Dr. Inocêncio de Souza Gorayeb and Dra. Ana Yoshi Harada (Museu Paraense Emílio Goeldi), which provided space and facilities during the development of this research.

\section{REFERENCES}

Anderson, R. S. 1993. Weevil and plants: Phylogenetic versus ecological mediation of evolution of host plant associations in Curculioninae (Coleoptera: Curculionidae). Memoirs of the Entomological Society of Canada 165: 197-232.

Bondar, G. 1941. Notas entomológicas da Baía. VII. Revista de Entomologia 12(3): 427-472.

Bondar, G. 1943. Notas entomológicas da Baía. XIII. Revista de Entomologia 14(3): 22-190.

Bondar, G. 1960. Novo gênero e espécie de Curculionídeos (Coleoptera) em palmeiras do Brasil. Revista Brasileira de Entomologia 9: 171-172.

VAlEnTE, R. M. \& I. S. GorayeB. 1994. Biologia e descrição dos imaturos de Conotrachelus imbecilus Fiedler (Coleoptera: Curculionidade: Molytinae) em frutos de Inga heterophylla. Boletim do Museu Paraense Emílio Goeldi, série Zoológica 10(2): 253-271, 18 figs. 